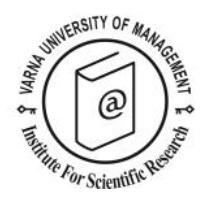

\title{
Social network analysis in tourism for improving marketing strategies. Understanding tourists' behaviour through their customer journey.
}

\author{
Tatiana David-Negre ${ }^{1 *}$
}

${ }^{1}$ Universidad de Las Palmas de Gran Canaria. Calle Saulo Torón, 4 - Universidad de Las Palmas de GC, Campus
Universitario de Tafira, Módulo E - Planta o - Derecha, C.P. 35017 - Las Palmas de Gran Canaria, España
Phone: +34 928454977. E-mail: tatianadavid12@gmail.com
${ }^{*}$ Corresponding author

Supervisors: Sergio Moreno-Gil and Juan M. Hernández

Institution awarding the Ph. D. Degree: Universidad de Las Palmas de Gran Canaria

Date of defence: o8 November 2019

Citation: David-Negre, T. (2020). Social network analysis in tourism for improving marketing strategies. Understanding tourists' behaviour through their customer journey. Doctoral Dissertation Summary. European Journal of Tourism Research 26, 2613. 


\section{Goal and objectives of the dissertation}

The goal of this study is to obtain a better comprehension of the tourists' behaviour at different stages of the customer journey, specifically, before and during their holidays, and the interrelationships of the agents that are part of this sector. In order to achieve this goal, the following objectives are addressed:

- To understand the European tourists' behaviour in relation to the e-tourism platforms consulted when choosing their next destination and their implications in the management and marketing of destinations, employing an alternative methodology.

- To further understand the behaviour of information search by tourists, and the role of the economy of platforms (collaborative) according to generations.

- To understand the expenditure patterns of the tourists per activity day-by-day, and how the centrality (importance of an individual or a particular activity) influences spending at the destination.

\section{Methodology}

To achieve the proposed objectives, some tools of social network analysis (SNA) were applied. This methodology analyses networks formed by nodes (tourist platforms, activities and attractions of the destination, and tourists) and it contributes to present a clearer overall perspective to the interrelationships among them.

These networks were analysed from a global to a local perspective. Global analysis describes the general characteristics and detects groups and subgroups. Local analysis helps to discern the most important individuals (König and Battiston, 2009).

Specifically, we performed the following analyses: network density, clustering coefficient, average distance, QAP correlation, community detection, centrality metrics and ego-networks (Freeman, 1978, Borgatti and Everett, 1997, Borgatti et al. 2002). UCINET 6.591 and NetDraw softwares were used to perform the analyses and represent the networks (Borgatti et al. 2002, Borgatti et al., 2018).

This analytical technique was complemented with others such as statistical analyses (multiple regression) and differences/heterogeneity tests (Mann-Whitney $U$ test).

Data for the first two chapters were collected through a computer-aided Web interview (CAWI). The target population of these studies included tourists aged 16 and over, belonging to 19 European countries (Austria, Belgium, Czech Republic, Denmark, Finland, France, Germany, Ireland, Italy, Luxembourg, Norway, Poland, Portugal, Russia, Spain, Sweden, Switzerland, The Netherlands and United Kingdom), and who consulted online platforms to plan their holidays. Particularly, tourists were openly asked about the platforms used to obtain information. The sample involved 13,243 tourists and 178 platforms for the first chapter and 104 platforms for the second.

The information for the third chapter was gathered through questionnaires conducted at Gran Canaria's airport. The tourists were asked to answer every day to these questionnaires, and included questions related to the conducted activities. In order to select the activities to be taken into account in the analysis, first of all, leisure companies, Destination Marketing Organisations (DMOs) representatives and tour operators were consulted. At a later stage, a focus group was carried out, obtaining 27 main activities. Overall, 483 surveys were collected at the end of the period. 


\section{Results}

Four key platforms belonging to the European platform network were identified, named the "big four": Google, Facebook, Booking and TripAdvisor, where Google is considered as the main gateway to that ecosystem. Moreover, these represent the major connectors, accounting for the key platforms. None of these platforms corresponds to the traditional agents of the sector. It was also found that the behaviour of European tourists in terms of seeking information on tourist destinations is diverse according to nationality and generations.

Europe can be described, on the one hand, as a single market for the four major platforms and, on the other hand, as a fragmented market in terms of some sources of information. This changes the scenario where long-established companies, but also new internet companies are competing for market power. Moreover, the results demonstrate that, some of sharing economy platforms are among the most relevant platforms in Europe although their importance is less than expected.

Once the tourist's behaviour has been analysed during the phase prior to visiting the destination, interest arises in analysing how they act at the destination in terms of network behaviour. The results identified a core-periphery structure in the activities network. Activities located in the core are the greatest performed and are located mainly near the accommodation. On the other hand, activities performed on a smaller extent located in remotely areas were identified as peripheral activities. Some of the latter were classified as "excluding activities", and decreased the chances of performing more activities.

On the other hand, tourists who carry out the most popular activities fit the pattern of mass tourism, and tourists who carry out peripheral activities conform to the definition of "niche tourists". Some "opening activities" were also identified, mostly performed during the first two days, and which probably influence the configuration of activities carried out.

Passive activities, contemplative activities and those less frequently performed were found to reduce the expenditure per activity (total and average). In contrast, some activities produce an increased mean expenditure and total expenditure per activity.

\section{Theoretical conclusions}

This study describes the use of e-tourism platforms by European tourists for selecting their next holidays, and the interconnections of platforms. It has also contributed to the literature related to the platforms' interconnections and information search literature.

The study also confirms that the European e-tourism network is absolutely complex where distinct types of platforms coexist and compete for market power, helping to comprehend with a new perspective how the tourist generations use the platforms when select their holidays, and the interconnections between platforms.

This research also involves a methodological contribution when applying the SNA together with other techniques for the study of the relationships between tourists, activities and spending.

\section{Practical application of the dissertation}

This research can help both public and private organisations to respond to some of the problems faced by the tourism sector. 
Tourism companies and DMOs can use the information resulting from this work to improve their segmentation and communication strategy, both in conventional media and through social media and others. For example, when it comes to the main four platforms, known as the big four, destination managers must employ common marketing strategies for almost all the countries and generations. However, they should also use marketing strategies adapted to each of the segments studied since differences in the use of the platforms by countries and generations were identified. Achieving a greater understanding of how tourists from the major European countries in terms of tourism use online platforms to choose their holidays is a strategic factor for their success.

The results obtained in the study enable the managers of the DMOs to choose the strategies to be used for the development of products for the portfolio of activities with the objective of increasing destination spending. Specifically, destination managers should promote activities with a higher expenditure amongst the tourists they receive.

In general, from this thesis, several strategies are recommended to improve the segmentation, communication, promotion and distribution used in a digitalised, multicultural and global environment, that help to optimise and develop products and services and to improve the competitiveness of the destinations, and with special attention to the behaviour of the consumer before and during the travel.

\section{Content of the dissertation}

\section{Abstract of Chapter 1}

This study evaluates the use of internet by 13,243 tourists from 19 European countries. The research was conducted using a CAWI interview and employs SNA in order to detect the most important platforms in the European e-tourism network. Revealing the structural characteristics of the network in the etourism ecosystem. The results show the principal role of Google, Booking, Facebook and TripAdvisor, but also detects differences by countries. Through this analysis, European tourists' behavior is better understood in relation to the use of the Internet and the choice of destinations, from a novel perspective.

\section{Abstract of Chapter 2}

An alternative supplier of traditional industries is the platform economy (PE). Furthermore, the PE has had a significant growth in tourism where the sharing economy has had a great impact. Thus, the aim of this study is double. First, it analyses the importance of the sharing economy within the PE. Secondly, it explains the dissimilarity amongst generations (Baby Boomers, $\mathrm{X}$ and $\mathrm{Y}$ ), in relation to their use of PE. In order to improve destination marketing strategies, the methodology of SNA was applied to 13,243 tourists from 19 European countries.

\section{Abstract of Chapter 3}

This chapter tries to detect tourists' spending patterns in relative to the activities done daily in Gran Canaria. Applying the social network analysis, a structure recognised as core-periphery was identified for the network of tourists and activities. On the other hand, a multiple regression model was used to analyse the effect of the core-periphery pattern on destination expenditure. In addition, variables associated to travel and sociodemographic variables were incorporated. This research expose that we applied an innovative method to study the interrelation between activities and tourists. 


\section{References}

Bonacich, P. (2007). Some unique properties of eigenvector centrality. Social networks, 29(4), 555-564. Borgatti, S. P., \& Everett, M. G. (1997). Network analysis of 2-mode data. Social networks, 19(3), 243-269. Borgatti, S. P., Everett, M. G., \& Freeman, L. C. (2002). Ucinet for windows: Software for social network analysis. Harvard, MA: Analysitc Technologies Harvard.

Borgatti, S. P., Everett, M. G., \& Johnson, J. C. (2018). Analyzing social networks. Sage.

Freeman, L. C. (1978). Centrality in Social Networks Conceptual Clarification in Hawaii Nets Conferences. Social Networks. An International Journal of Structural Analysis Lausanne, 1(3), 215239.

König M, Battiston S (2009) From graph theory to models of economic networks. A tutorial. Lect. Notes Econ. Math. Syst. 613:23-63.

Received: 06/02/2020

Accepted: 15/05/2020

Coordinating editor: Faizan Ali 